\title{
Preface
}

\section{Location and History}

NICOLAS BARREYRE, MICHAEL HEALE, STEPHEN TUCK, AND CÉCILE VIDAL

History is all explained by geography.

-Robert Penn Warren

Perhaps the most famous European observer of new worlds-and certainly the most beloved of generations of children-was Lemuel Gulliver, the crotchety old seafarer who returned to England in the early eighteenth century. His fantastical tales of the miniature people of Lilliput and the giants of Brobdingnag, the flying island of Laputa and the savage Houyhnhnms, captured the public imagination then and have never been out of print since. Jonathan Swift's rather subversive purpose in writing Gulliver's Travels, of course, was to use the fictional traveler's consideration of foreign lands to critique the structure and ideological presuppositions of society more generally-an aim so subversive, in fact, that Swift took precautions to ensure that there was no evidence to prove he was the author.

This book is (sadly for the reader) less subversive in its intent and (sadly for the authors) less likely to have such an enduring publication record. Even so, it takes as its departure point what soon became a standard trope after Gulliver: the outsider as privileged observer. In modern times, few countries have been more observed than the United States, and few countries have sent more observers there than those in Europe-Alexis de Tocqueville, James Bryce, Sándor Bölöni Farkas, Henryk Sienkiewicz, and numerous others have followed in Gulliver's fictional footsteps to observe a new world that was often as imagined as it was real. Professional historians arrived in the early twentieth century, their ranks swelled dramatically in the mid- and late century, and 
European universities now collectively employ several hundred historians of North America in permanent positions. ${ }^{1}$

No doubt each one has been asked at some point: what difference does your position as an outsider make to your scholarship? Down the years, many answers have been offered, not least by senior American academics-from the inaugural speech by the president of the American Historical Association, in I 884, warning that "disengaged and disentangled" outsiders must, "as a rule, give the maximum of labor to a minimum of result," to the 1992 call by the editor of the Journal of American History for the incorporation of international scholarship into American historiography, with the prediction that fresh perspectives would reinvigorate the discipline at home. ${ }^{2}$ Whether positive or negative, though, all such speculation has shared the presumption that outside observers would have a distinctive approach.

This proposition might look like common sense, yet it carries many unexamined assumptions about the practice of writing history-assumptions that this book seeks to deconstruct. Nationality-belonging or not to the nation whose history one writes-is not an explanation in itself. As we hope this book shows, the necessarily comparative context of writing a foreign nation's history highlights the fact that such conditions cannot be reduced to the identity of individuals. Behind the status of "foreign" historian-with its inevitably outside perspective-are more complex, interesting, and invariably unexplored influences of audiences, institutions, and academic structures and cultures, which are often, but not always, national in scope. Thus we suggest that any investigation into the question of perspective should quickly lead to a much broader and more important epistemological issue: how do institutional and cultural factors shape the writing of history?

In a collective endeavor gathering twenty-four scholars from eleven European countries, we explore this subject by examining one case study: American history as written in Europe. In other words, we borrow Swift's device of observing a foreign society in order to investigate a broad issue in the very structure of any society-in this case, the observers are historians based in Europe, the foreign society is the North American colonies or the United States, and the broad issue is the institutional and cultural influences that shape historical writing. This is why we are not offering a state-of-the-field survey of European historiography, and even less do we attempt a report on the European contribution to American history. ${ }^{3}$ Rather, it is the role of location in the writing of history that interests us, so we have focused primarily on the work of 
academic historians, although-as some of the chapters note-others have published insightful American histories too. ${ }^{4}$ This investigation thus also carries implications for the writing of American history in the United States, since U.S. scholars too are conditioned by their cultural and institutional contexts. In short, this case study carries implications for the writing of history wherever it is written. Place matters.

Apart from acknowledging academic debts and sharing some biographical details in a preface and hinting at the present-day implications of their work in an epilogue, most historians rarely reflect publicly on the constraints and opportunities that have shaped their scholarship. This may be because the academic and social environment that each historian works within provides the intellectual air that he or she breathes-seemingly natural, perhaps even universal, and thus easy to take for granted. It may also be reassuring for historians to see themselves as free-floating individuals, whose innovative research paths are the products of their own, purely intellectual choices. But we contend that even in a democratic age, historians float a little less freely than might be assumed. Our means of illuminating the often hidden institutional and cultural factors that shape historical production is to examine why European writing about the United States and its antecedents remains distinctive, even at a time of increased academic globalization. ${ }^{5}$

European historical writing about early North America and the United States provides a suitable case study for both its exemplarity and its peculiarities (in addition, of course, to it being our own turf). Europebased scholars of the United States are but a subset of all historians specializing in foreign nations (or, in some cases, former colonies) in a profession that still bears the heavy imprint of its national, even nationalist, past. ${ }^{6}$ Yet the United States is anything but a typical foreign country, of course, not least because of the current hegemony of the American academy. ${ }^{7}$ European historical writing has a distinctively long and entangled relationship with its U.S. counterpart. ${ }^{8}$ In the twenty-first century, most European historians of America are much more in touch with their fellow specialists in the United States than they are with one another, but while that condition favors American hegemony, it only changes rather than overturns the influence of being based in Europe. If all politics is local, so is all history, and European historians, like all historians, are conditioned not only by the time in which they write but also by the places from which they write.

European writing about the United States and its antecedents also affords opportunities for comparisons within, among, and beyond 
European nations and over time. Individually, each historian of the United States in Europe is at the margins of both the U.S. academy and his or her national academy, both usually well stocked with historians studying their own nation. Even the colleagues of historians of British, French, Dutch, and Spanish colonies in early North America, who should be considered historians of Great Britain, France, the Netherlands, and Spain, often see them as historians of foreign countries or extraneous territories-a reminder that comparisons among the types and periods of American history matter too. Meanwhile, at the collective level, despite the uniformizing pressures of European bureaucracies and globalized scholarship, the national academies of Europe remain diverse both among and within themselves (we also recognize that the American academy is far from monolithic). The essays in this book make use of each of these comparisons to highlight the evolving structural and cultural influences that shape scholarship.

American and European historians of the United States are not mutually exclusive tribes. The United States possesses the largest and bestresourced historical academy in the world, and it has recruited many European scholars, including to posts in American history. Conversely, the U.S. government and philanthropic organizations have done much to encourage the study of American history in Europe, as the following chapters acknowledge, particularly after the Second World War, and European universities have welcomed a steady flow of American historians eager to make their expertise available. Mostly these scholars have visited European universities for a semester or a year, though a few have chosen to make their careers in Europe. So although even academics who study foreign lands overwhelmingly make their careers in the particular cultures and institutions of their own countries, those circulations, which have intensified recently, are part of our daily experience too. We hope that you will find in this book a point of comparison and connection from which to consider broad questions of historical production.

Considering the question of place is timely for historiographical and professional reasons. In recent years the writing of United States history has become a global preoccupation, while leading American practitioners have championed its internationalization by incorporating foreign scholarship. This has spurred voluminous discussions of American history in an international or transnational context-but virtually no discussion of the internal dimensions of historiography. ${ }^{9}$ Meanwhile, 
the few, invaluable surveys on teaching and writing U.S. history in particular countries abroad often serve more as barometers of global interest in U.S. history than as analyses of their commonalities or differences. ${ }^{10}$ Additionally, broad historiographical work on U.S. history rarely addresses the fact that a minority of practitioners neither are American nor live in the United States (or the obverse, that American history is overwhelmingly written by Americans). This is true even of works that seek to address how scholars' identities (as members of a particular minority group or gender, for instance) might affect their scholarship. ${ }^{11}$

To analyze how and why historians' writing beyond borders might matter is really to ask what shapes their point of view. This is, at its core, a spatial way of approaching historiography, seen as a common but uneven field where all historians are located, shaped not only by intellectual endeavors but also by career demands and institutional constraints and opportunities. Studying American history written from Europe, we hope, might thus answer two questions by linking them together: How does location, or positionality in that field, shape scholarship? And how does thinking of U.S. history written in the United States relative to U.S. history written elsewhere (and vice versa) help find new, more integrated perspectives or paradigms?

To explore the question of why place matters, we have chosen an analytical rather than country-by-country approach. Each chapter tackles a different aspect of a common question: why location matters to history writing, and what it tells us about the factors that shape scholarship. Each chapter is multiauthored by scholars from different European countries (with input from other scholars involved in this book, and beyond), allowing for comparisons among European contexts and between the United States and Europe. The reflections presented here are not meant to be definitive-many are open-ended and tentative. While focusing on a common question, each team of authors was free to come to their own conclusions-and did so. The authors have varied views on how their positions in Europe have made a difference (if at all) to writing about the United States and early North America. Our hope is that their observations and conclusions will be stimulating enough to (re)start a transnational discussion about the historiography of U.S. history and wide-ranging enough to join discussions of writing history across borders and reflections on historical writing more generally.

With these ideas in mind, we have organized the book in four parts. The first three take the example of European academies to explore 
specific aspects of the effect of location on writing American history. The fourth brings together reactions to these chapters from scholars of U.S. history and advocates of internationalizing history from other parts of the world, thus broadening the discussion and suggesting further routes of inquiry.

Part I is a single, long chapter that presents an overview of the European historiography of the United States from the late nineteenth century to the present. It is not, simply, a survey. Rather, its originality lies in teasing out common patterns across-and noting differences among-European academies. By taking the long view, it identifies some of the recurring preoccupations in this scholarship, such as the privileged position accorded to American political and constitutional history, a wariness of exceptionalist claims, and fascination with the American experience of race. European writing nonetheless has changed over time and varied according to place, and this chapter locates a number of chronological and geographical watersheds, as this historiography has taken new directions following the interaction of local circumstances with global or other pressures. The existence of totalitarian regimes in a number of major countries in the mid-twentieth century and beyond, for example, inevitably profoundly affected historical scholarship. By localizing a perspective on the historiography of the United States and by showing to what extent European and non-European historians of the United States share common historiographical grounds, this chapter demonstrates that location-in Europe-has indeed made (and continues to make) significant differences to the patterns and purposes of U.S. historical writing.

Part 2 then analyzes this impact. We focus on three aspects of how local contexts might influence the kind of European scholarship produced on the United States and the colonies and territories from which it was formed: politics, institutions, and audiences. It might be expected that during the Cold War, Soviet historians of the United States would offer a different perspective from that of, say, British scholars keen to nourish the "special relationship," but political influences also affect academic historical writing in much more subtle, and interesting, ways. Through a wide array of examples, chapter 2 explores how local political issues and the way they relate to the wider world play into the interest in U.S. history, the topics scholars study, and the approaches they use. To sustain professional and public support for their activities, for example, European historians need to find something in the American experience that touches a chord with domestic audiences, something 
that demonstrates relevance. This chapter shows how relating history to the present is contingent on local contexts and on traditions in national academies.

Chapter 3 focuses on institutions and academic structures. It explicates some of the varying shapes that academic careers take in Europefrom the requirements of $\mathrm{PhDs}$ to the constraints of the job market and the expectations of professors-and the consequent effects on research and writing in order to explore the wider issue of how institutional demands, and the position of scholars of the United States in their academies, impact the scholarship they produce. It also discusses the tensions experienced by such European scholars, who have both to engage with U.S. historiography and to conduct research that makes sense to their European colleagues who are not American specialists, demands that can pull in opposite directions. The late German historian Willi Paul Adams once observed of the dilemma facing European historians of the United States that "perhaps the best solution is to think globally, act European and publish in the United States." 12 One mark of the globalization of scholarship is the very recent tendency for recognition by the American academy to be a criterion for the promotion of Americanists in some European countries.

Chapter 4 takes up the theme of a variety of influences in a common field, deconstructing the outsider-insider binary by looking at the various intellectual milieus that historians of the United States deal with in their professional and daily lives. It approaches U.S. history as a field that intersects with a range of audiences, which scholars might or might not engage with, depending on their location in the field. It also reflects on a number of taken-for-granted conventions, for example in written style, for what such habits or conventions may reveal about the distinctions that shape European historians' exercises in American history. Finally, it addresses the complex problem of language, which is a larger question than translation alone. For example, no complete American history can be written without considerable attention to race, but, as chapter 4 notes, when the word-or rather concept-is translated into European languages, it carries differing connotations, which can affect how the history is written. Moreover, though George Bernard Shaw may have been frivolous when he said that Britain and the United States are divided by a common language, even in those two countries particular usages have different meanings..$^{13}$

Taken together, these three chapters confirm that individual idiosyncrasies cannot, on their own, account for historiographical trends. To 
the contrary: these chapters offer three views of how the embeddedness of scholars in particular contexts can shape-by both constraining and providing opportunities-their scholarship. They consider oftenunacknowledged pressures and argue that if we think of U.S. history as space, then each scholar's position in that space matters.

From there, part 3 explores the ways that location (or rather, some of the political, institutional, and cultural pressures that part 2 discusses) can change perspectives on supposedly shared paradigms, often in unexpected ways. Even though the majority of European historians of the United States now work on that country's domestic history, usually without explicit transnational or comparative elements (excepting the burgeoning field of Atlantic history), we focus here on approaches that have sought to internationalize U.S. history and thus might be presumed to be universally applicable. Yet even with decentered U.S. history, the position of the author can still matter. A historian who writes about a foreign country is necessarily engaged in a comparative exercise, even if only implicitly. Chapter 5 confronts the long traditions of comparative history, examines the distinctive trajectories of European- and U.S.-based approaches to the same transatlantic comparison, and offers explanations for the differences, which reveal something about each nation's history. The chapter also positions comparative history as it is currently practiced in relation to the more fashionable approaches of transnational history, histoire croisée, and global history.

Of all transatlantic connections, diplomacy and migrations have long most interested European historians. Chapter 6 deals with both, although it is mainly concerned with diplomatic history. It considers the impact of location differently than other chapters, arguing that the evolving geopolitical positions of Europe and the United States cannot but inform the European historiography of American foreign relations. It also demonstrates that a transatlantic divide has separated American and Europeanbased historians of American geopolitics in some intriguing ways, not least because they have not shared the same paradigm of power. American scholars tend to focus on the projection of U.S. power and its impact abroad and at home; European scholars often reflect on power's relational dimension and how the interplay of influences between the United States and Europe can modify or transform American policies or programs. A new generation of European scholars, now well versed in U.S. historiography, have moved this approach to power away from its initial focus, on (often bilateral) transatlantic relationships, and toward the 
more international or transnational relationships of which both the United States and Europe are parts.

This attraction to all sorts of transnational and global history is also the subject of chapter 7. It looks at "early American history" and its multiple reconfigurations from the I960s to analyze the impact of location on the conceptualization of historical frameworks. It argues that, because of location, U.S.-based early North Americanists have a tendency to privilege Atlantic over imperial history, while the imperial rather than the Atlantic turn more often tempts their European colleagues. However, the impact of location comes from multiple factors, such as local institutional constraints, academic cultures, and power relationships among academic systems that are increasingly connected and can have complementary or contradictory effects. This leaves room for historians to make individual choices, develop alternative strategies according to audiences, and multiply historiographical experimentations.

After these analyses of various aspects of and influences on European scholarship, part 4 opens up the debate by inviting prominent scholars from a variety of other regions of the world to reflect on some of the elements thus put on the table. Most of them have also long advocated the internationalization of U.S. history, notably Thomas Bender in the United States, Ivan Kurilla in Russia, Ian Tyrrell in Australia, and Natsuki Aruga in Japan. Scholars with instructive transnational experiences offer other perspectives: David Nye, an American long resident in Denmark, and François Furstenberg, a dual U.S.-French citizen who has been making his career in Canada. With their authors in very different locations, not just geographical but in historiography and the American academy, the essays in part 4 broaden the earlier comparisons and thus extend their analysis and suggest further topics for investigation.

So as, like Gulliver, you embark on the journey of the following chapters, we bid you bon voyage in the hope that the musings of the travelers you will encounter in these pages will help to forge a discussion on our common endeavor of writing history, whether American or some other kind, and on the often hidden factors that shape our scholarship. We also hope that these reflections will contribute to the common goal of renewing the historiography of the United States (and the colonies and territories that formed it). 
This page intentionally left blank 